\title{
MAGISTER
}

MBA

ALANZA INTERNACIONAL CO
娄 NNIVER RITYOF
NOTRE DAME

Mendoza College of Busints

Más de 500 exalumnos
- Clases viernes y sábado

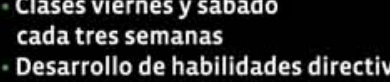

Proyecto de emprendimiento

www.uahurtado.cl/mba

MAE

MASTER OF ARTS

N ECONOMICS

(6)

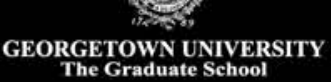
Más de 300 graduados
'Acreditido porr años

\section{MAPE MGP}

MASTER OF APPLIED MAGISTER EN GESTIÓN

MAGISTER EN

ECONOMIA APLICADA

- DOBLE TITULO CON:

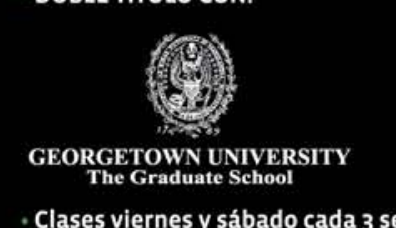

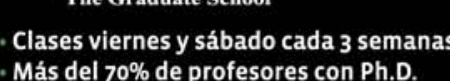

Más del $70 \%$ de profesores con Ph.D.
wwwweconomia

\section{DERERSONAS EN}

Clases viernes y sábado
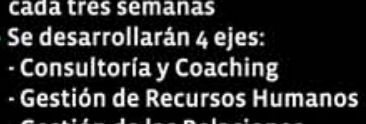

Personas en Organizaciones www.uahurtadoct/men

Contacto - magarcia@uahurtado.cl - Erasmo Escala 1835, Metro Los Héroes - Teléfono :(56-2) 6920289

\section{INGENIERIACOMERCIAL}

* Mención en Administración de Empresas y Mención en Economía

* Con un año adicional de estudios en la U. Alberto Hurtado, los alumnos pueden obtener el grado de Master of Arts in Eco* $90 \%$ de nuestros académicos son doctores o magister en su
especialidad

Contacto - corellan@uahurtado.cl - Erasmo Escala 1835, Metro Los Héroes - Teléfono (56-2) 6920386

\section{INGENIERIA COMERCIAL PARA PROFESIONALES}

Grado académico

Ciencias de la Administración de Empresas

Título

- Ingeniero Comercial, mención Administración de Empresas

Horario

Lunes, miércoles y viernes de 19:00 a 22:30 hrs.

Más un sábado al mes de 9:00 a 13:30 hrs.

Duración

6 trimestres más examen de grado
Dirigido a

Ingenieros de Ejecución en: - Administración de Empresas - Marketing - Negocios Internacionales Contadores Auditores Administradores
Demasiada transparencia Por Eduardo Abarzúa

Recientemente el Consejo de Transparen- rar la competividad, parece más lógico forcia tuvo dos actuaciones que merecen ser malizar auténticos directorios profesionales, comentadas. Por un lado, en el marco de la que con independencia velen por los recurLey de Acceso a la Información Pública, obligó a publicar las remuneraciones de cada Director, Presidente Ejecutivo o Vicepresidente Ejecutivo y Gerentes responsables de la dirección y administración superior de las empresas públicas. Por otro lado, en la Deciel caso de los concursos de primer y segundo nivel de la administración pública, "realizar una versión pública de los informes de evaluación de la terna o la quina propuesta, $y$ en particular, de la persona finalmente designada en el cargo".

Si bien es dificil estar a priori en contra de trasparencia de los actos y fundamentos de las decisiones públicas, desde el punto de vista del bien perseguido el panorama no es simple. No se mejora la competitividad de estas empresas publicando los montos de las remuneraciones de sus directores y ejecutivos: al contrario, se instala una desventaja: se informa a la competencia de las sos del Estado.

Respecto a la publicidad de quinas y ternas en concursos públicos, la pregunta es obvia. ¿postularia Ud. a un cargo si sabe que se dara a conocer su nombre como parte información quina $y_{1}$ también parte de a sus capacidades laboras? Por supuesto ue no: revelar información sensible soandidatos no es un bien público. Si 10 s atraer $y$ retener los mejores profesionales del mercado, mejorando las rentas ofrecidas vasimilándolas a las del sector privado. La transparencia como referente de la los impactos que provoca; elevarla a la categoría de bien público hace perder de vista otro tipo de referentes que tienen el mismo valor en la toma de decisiones y la gestión del Estado.

*Ph.D. en Ciencias del Trabajo, U. Católica
de Lovaina. Director Magister en Gestion de el gráfico

AFP: ¿CÓMO LE VA A

LOS DUEÑOS?

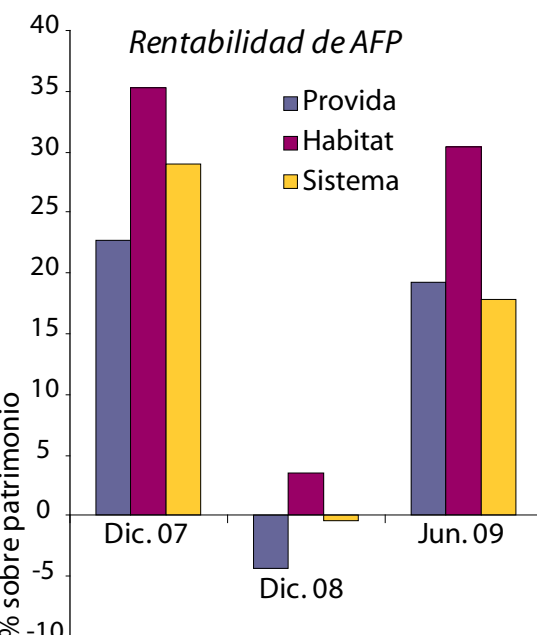

Juan Foxley $R^{*}$

Una de las virtudes de la regulación vigente sobre el sistema de capitalización individual es que la rentabilidad de los dueños de AFP sigue resultados parecidos a los de los afiliados. La razón es que las administradoras están obligadas a mantener una rese va (encaje) en bonos, acciones y otros, equivalente al uno por ciento del valor de cada fondo. Y con la misma diversificación. Asi, por ejemplo, entre un 52 y un 65 por ciento de los activos propios de las AFP más grandes (Provida y Habitat, respectivamente) correspondian a encaje al primer se-

exigencia de encaje obliga a las teris prulación representa uniliados. La gerdia al desalentar la temerisad en la búsqueda de mayores rentabilidades para los fondos de los afiliados. Como se observa en el gráfico, las AFP muestran pérdidas contables en 2008 : destaca el retorno negativo de Provida, la empresa más grande.

Durante 2009, la recuperación de precios de los activos ha mejorado la rentabilidad de los fondos de los afiliados y, en menor medida, el retorno al patrimonio de las administradoras. 